\title{
THERMAL ANALYSIS IN DRILLING OF EX VIVO BOVINE BONES
}

\author{
M. G. FERNANDES ${ }^{*} \S$, E. M. M. FONSECA ${ }^{\dagger}$, R. N. JORGE*, \\ M. VAZ* and M. I. DIAS* \\ *LAETA, INEGI, Faculty of Engineering \\ University of Porto, Porto, Portugal \\ ${ }^{\dagger}$ LAETA-INEGI Department of Applied Mechanics/UMNMEE \\ Department of Applied Mechanics \\ Polytechnic Institute of Bragança, Bragança, Portugal \\ \$CITAB, University of Tras-os-Montes e Alto Douro \\ Vila Real, Portugal \\ §mgfernandes@inegi.up.pt
}

\author{
Received 20 November 2015 \\ Revised 23 January 2017 \\ Accepted 24 January 2017 \\ Published 13 July 2017
}

\begin{abstract}
Bone drilling is a common procedure in Medicine, mainly in traumatology and orthopedic procedure for fractures fixation and in reconstructive surgery. The success of this surgical procedure is dependent on many factors, namely, on heat generation control during the bone drilling. The main concern in bone drilling is the mechanical and thermal damage of the bone induced by inappropriate parameters such as drill speed and feed-rate during the drilling. This study focuses on the temperature generated during drilling of cortical bone tissue (bovine origin) and solid rigid polyurethane foams with similar mechanical properties to the human bone tissue. Different parameters such as drill speed, feed-rate and hole depth were tested. All results showed that improvement of the drilling parameters and the drill temperatures can be estimated. It was concluded that when the drill speed and feed-rate were higher, the bone temperature increase was lower. The obtained results of temperature in the drilling process of polyurethane foam blocks or bovine bone were compared with a good agreement in between both.
\end{abstract}

Keywords: Drilling process; temperature; polyurethane foam block; ex vivo bovine bone.

\section{Introduction}

Bone drilling is an essential step in many surgical procedures, such as bone fracture reconstruction with resource to metallic implants, predrilling for screws placement or insertion of external fixators, and other techniques in orthopedic surgery. ${ }^{1,40}$ The success of such procedures is dependent upon the quality of the drilling

$\S$ Corresponding author. 
process and has the purpose of minimizing the associated injury to the surrounding tissue. However, complications could occur during bone drilling, such as mechanical and thermal damage of bone and also to the surrounding tissue. ${ }^{35}$ One of the main problems is the generated heat during bone drilling, due to shearing of the material and friction between the cutting surface of the drill bit in contact with the surrounding bone tissue and possible bone fragments formed during the drilling procedure. $^{2-4}$ When the obtained temperatures during the drilling operation reach the limit supported by bone tissue, bone necrosis could occur. ${ }^{5,6}$ The level of thermal damage to the living bone tissue is related to the magnitude of temperature elevation and the time to which the bone tissue is exposed to the damaging temperatures. ${ }^{7,31,41}$ For recording the heat generated in real time, the scientific literature has only referred to two methods until now. The use of thermocouples, which enable direct measurements or indirect estimating by infrared thermography. Although thermocouple technology is well established, the results of the studies on its use are still not uniform. ${ }^{8}$ One of the problems of this technology is its ability to detect local temperatures only. The present technology does not allow the production of an overall thermal profile or the measurement of heat that has leaked. This problem does not exist with infrared thermography, which is described as being more accurate and with a lower probability of error. ${ }^{8,9}$ Whenever possible and so as to reach more accurate results, both methodologies must be used in association.

Nowadays, there are many studies in the literature regarding the recording of temperatures reached during bone drilling processes. Eriksson and Albrektsson, ${ }^{10}$ for example, concluded that the threshold levels for thermal necrosis in the living rabbit bone tissue were set at $47^{\circ} \mathrm{C}$ for $1 \mathrm{~min}$ of heat exposition time. Lundskog ${ }^{6}$ also carried out his studies on rabbits and concluded that a temperature of $55^{\circ} \mathrm{C}$ for a period of $30 \mathrm{~s}$ could cause the irreversible death of the bone cells. Bonfield and $\mathrm{Li}^{7}$ demonstrated that irreversible bone changes occur when dog femoral bone tissue were heated to $56^{\circ} \mathrm{C}$ in vivo. These results reflect the importance of the bone drilling studies when improving the chances of avoiding thermal necrosis.

Currently, it is known that the generated temperature during bone drilling is directly associated with the drilling parameters, such as drill speed, feed-rate, drill bit geometry, drill force, hole depth and also bone density. ${ }^{6,11}$ Control of these parameters is essential to improve the drilling conditions, reduce the generated heat and to minimize the bone damage. Based on temperature measurements, several studies have been carried out to assess various parameters that influence surgical drilling into bone. ${ }^{1,12,13,32-39}$ However, the complexity of the process and the extensive number of variables involved complicates the statement of concluding remarks. Experimental models coupled to other methodologies, such as computational models, has been a common practice in this type of analysis. Recently, Marco et $a l .{ }^{14}$ has made a bibliographic review of the main contributions in modeling of bone cutting, including the drilling process. They concluded that the majority of the works involve the finite element method. Some models only include thermal issues assuming the application of a heat source without simulation of chip removal, but in 
other works, chip removal is simulated. Our recent studies have also demonstrated the importance of these numerical models in the analysis of drilling processes. Thermal and dynamic models were developed and validated based on experimental models of bone drilling. ${ }^{32,35}$

For the experimental models, the vast majority of models use biological materials to relate bone temperature with drilling parameters. A variety of cortical and cancellous bone types have been evaluated in surgical drilling studies, such as bovine and porcine. ${ }^{4,12,15,16}$ However, it is difficult to define a good method in such circumstances as the bone is a complex anisotropic biological tissue, with organic and inorganic components. The interaction of different components accounts for its complex mechanical and thermal properties, which are difficult to study due to sensitivity, test conditions and preparation of the specimens. ${ }^{17,18}$ Therefore, the ideal procedure is to replace the biological materials by engineering materials. In comparison with biological test materials, biomechanical test in standard materials do not require as many repetitions or the use of elaborate statistical tools. ${ }^{4}$ For this propose, there are a variety of synthetic bone materials available but polyurethane foam manufactured by Sawbones (Sawbones, Pacific Research Laboratories, Inc., Vashon. WA, USA) has been the most extensively used material in medical experiments, especially in surgical reconstruction, fracture fixation and drilling testing. The uniformity and consistency of its material properties makes rigid polyurethane ideal for comparative testing of various surgical procedures, medical devices and implants. ${ }^{19}$ To date, just a relatively few number of researches have directly compared bone drilling into biological tissues and synthetic bones. Although these surrogates are becoming increasingly used, a comparison of generated heat during bone drilling in bovine versus synthetic bone has not been performed, yet.

The main goal of this study was to analyze the temperature variation in the drilling processes and determine the effects of some variables with the objective of helping health professionals, by ensuring drillings within a safe zone and hence ensuring not damaging of bone tissue. For this purpose, feed-rate, drill speed and hole depth were evaluated during the drilling of fresh bovine bones and solid rigid polyurethane foams. During the drilling process in polyurethane foam blocks, the temperature was measured using thermocouples inside the material, and a thermographic camera was used to capture the surface temperature in the drill bit. In bovine bones only, the thermographic camera was used to measure the temperature in drill bit.

\section{Temperature Evolution in the Drilling of ex vivo Bovine Bones and Foam Blocks}

As previously indicated, the complex mechanical and thermal properties and the variation of the properties from samples taken from different bones of the skeleton, and from different individuals of the same species, outcome in variations in the measured temperature, although subject to identical drilling conditions in repeated 
tests. In order to isolate inhomogeneity and anisotropy effects in the specimen and conduct the experimental tests in an effective manner, drillings in ex vivo bovine bones and solid polyurethane foams have been selected for the first stage of the experiments.

\subsection{Bovine bones samples preparation}

In the ex vivo study, fresh samples of bovine femur were used. The bovine bone was chosen because it is one of the animal bones that most similarly replicates the characteristics of human bone tissue, and it has been shown that it can be used as a substitute for human bone. ${ }^{20,42}$ All samples were obtained from a local butchery, where they had been previously cleaned (muscle removed), as shown in Fig. 1. The bones were obtained after the death of the calves, with age of 9-12 months (no animals were sacrificed specifically for the purpose of the current study).

The experimental tests were performed a few days after obtaining the bone samples. In this case it is important to prepare and preserve the femurs correctly (frozen at $-20^{\circ} \mathrm{C}$ after wrapped with gauze swabs in physiological saline solution) and keep the properties until the day of the tests. In order to retain the mechanical and thermo-physical properties, the samples were prepared according to the guidelines established by Ref. 43. All samples were kept moist in saline solution with gauze swabs and stored in plastic bags at $-4^{\circ} \mathrm{C}$. Before the tests, bone samples were removed from freezer and completely thawed at room temperature for $24 \mathrm{~h}$.

Since higher temperatures are obtained in the cortical tissue, through a hacksaw, the bone epiphysis were removed just keeping the mid-diaphysis columns (Fig. 2).

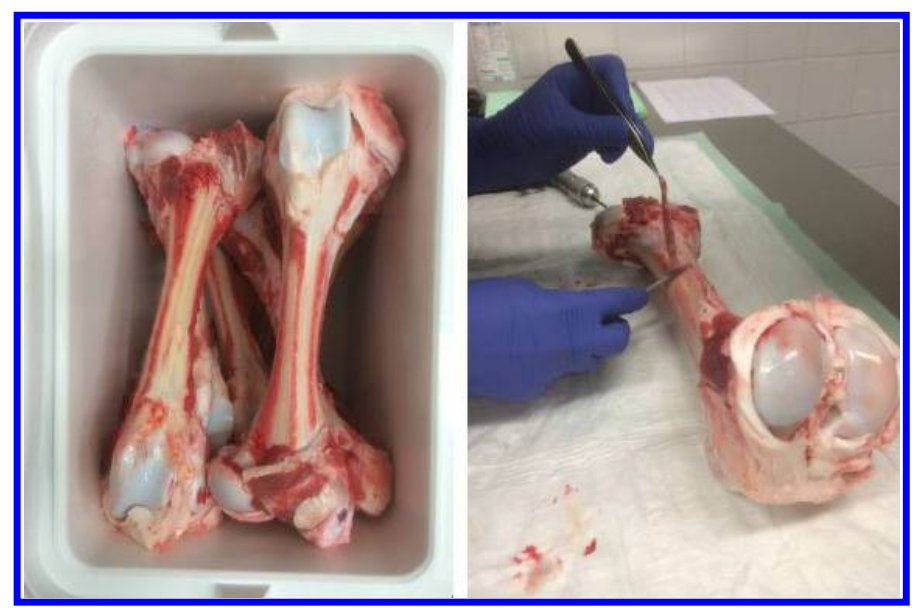

Fig. 1. Samples preparation for the experimental tests in ex vivo bovine bones. 


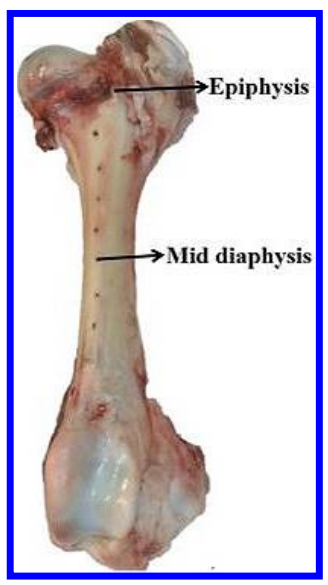

(a)

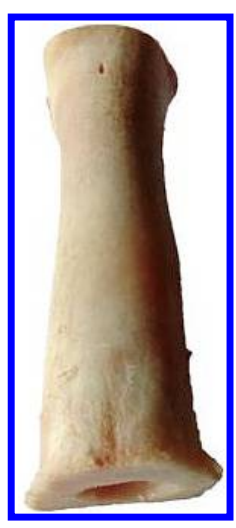

(b)

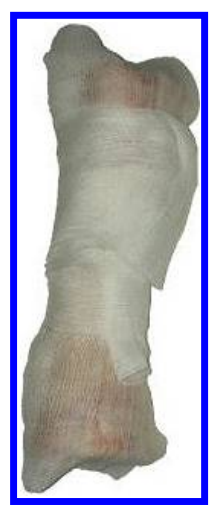

(c)

Fig. 2. Fresh bovine femur (a), sample cut from mid-diaphysis (b) and wrapped with gauze swabs in physiological saline solution (c).

The periosteum and bone marrow were also removed from the outer surface of the bone samples, as it clogs the drill flutes. ${ }^{21}$

The bone pieces have the approximate dimension of $120-150 \mathrm{~mm}$ in length with an average thickness of the cortical wall of $7-9 \mathrm{~mm}$. A total of eight test samples were prepared from the femur bones and each sample was numbered and divided to accommodate approximately six holes with $20 \mathrm{~mm}$ of distance between them.

\subsection{Experimental setup in bovine bone samples}

The overall experimental setup includes a temperature measurement system, a computer numerically controlled (CNC) machine for a constant processing with controlled parameters and a conventional HSS twist drill bit with $4 \mathrm{~mm}$ of diameter and a point angle equal to $118^{\circ}$.

The temperature system is based on the use of a thermal camera (ThermaCAM 365, FLIR Systems) which has been rigidly fixed to a tripod at a distance of $1.5 \mathrm{~m}$ from the drilling area. This method allowed to obtain thermal images of the bone and drill bit surface, before and immediately after drilling. Temperatures were measured in real time and the thermal image data were transferred to a $\mathrm{PC}$ for simultaneous analysis in appropriate software (FLIR QuickReport Software, FLIR Systems). The measured temperature is a function of the surface conditions, represented by their emissivity. The imposed parameters to the camera during image acquisition are listed in Table 1.

An experimental procedure was designed to evaluate the effects of drill parameters as well as to compare the results obtained with those obtained from synthetic bones. The overview of the experimental setup used in this study is shown in Fig. 3. All the drilled holes were carried out on femoral diaphysis at room temperature 
Table 1. Parameters used for the thermal image acquisition.

\begin{tabular}{lc}
\hline Parameters & Value \\
\hline Distance camera-drill bit surface & $1.5 \mathrm{~m}$ \\
Room temperature & $19^{\circ} \mathrm{C}$ \\
Emissivity $\varepsilon$ & $\varepsilon_{\text {stainless steel }}=0.70$ \\
& $\varepsilon_{\text {skin human }}=0.98$ \\
Relative humidity & $50 \%$ \\
\hline
\end{tabular}

without cooling. For the successive holes, a sufficient time was allowed for the bone and the drill bit to return to the initial conditions. The parameters used in all experimental tests are condensed in Table 2. Parameter combinations were selected to investigate either the influence of drill speed and temperature variation between biological tissues and synthetic bones.

\subsection{Experimental setup in polyurethane foam blocks}

To the drilling operations in the solid rigid polyurethane foams, two biomechanical test blocks supplied by Sawbones were chosen due to comparable mechanical properties to the human bone tissue. Foams are available in a range of sizes and densities. In this study, the foam density of $0.80 \mathrm{~g} / \mathrm{cm}^{3}$ (50 pcf) was selected, as

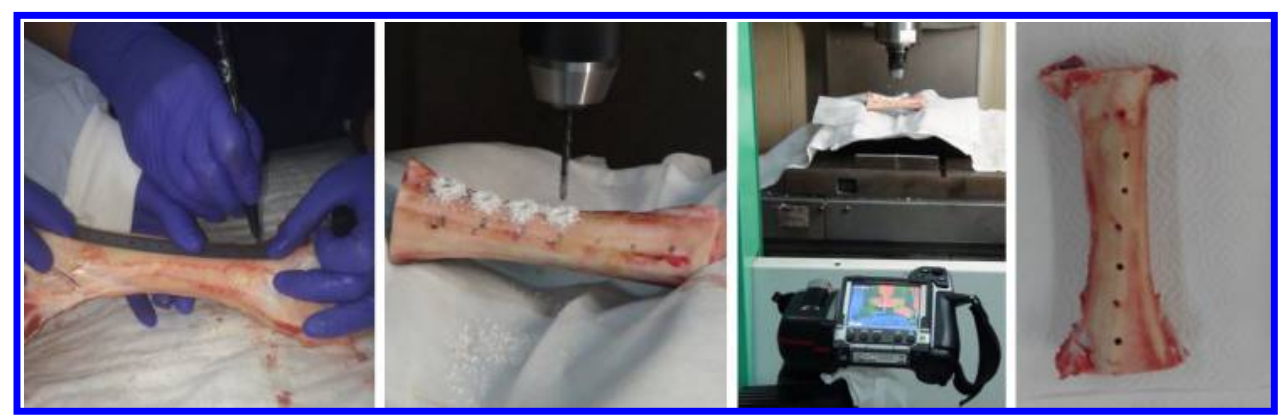

Fig. 3. Drilling operations of bovine bones.

Table 2. Parameters used in drilling experiments.

\begin{tabular}{lrrrrr}
\hline & \multicolumn{2}{c}{ Foam block } & & \multicolumn{2}{c}{ Ex vivo bovine bones } \\
\cline { 2 - 3 } \cline { 5 - 6 } Parameters & Bl1 & Bl2 & & Samples 1,2,3,4 & Samples 5,6,7,8 \\
\hline Drill diameter $(\mathrm{mm})$ & 4 & 4 & & 4 & 4 \\
Drill point angle $\left(^{\circ}\right)$ & 118 & 118 & & 118 & 118 \\
Depth of the holes $(\mathrm{mm})$ & 8 & 8 & & 8 & 800 \\
Drill speed, $\omega(\mathrm{rpm})$ & 800 & 900 & & 800 & 50 \\
Feed rate, $\mathrm{V}(\mathrm{mm} / \mathrm{min})$ & 50 & 50 & 50 & \\
\hline
\end{tabular}


representing the cortical bone, which was approved by the American Society for Testing and Materials for testing orthopedic devices and instruments. These materials are used as an alternative testing medium to human cadaver bone and offer consistent and uniform physical properties that eliminate the variables encountered when testing human cadaver bones. ${ }^{22}$ The polyurethane foam blocks have the same dimensions $(130 \times 180 \times 40 \mathrm{~mm})$ and were identified as $\mathrm{Bl} 1$ and $\mathrm{Bl} 2$ in accordance with different drilling parameters (Fig. 4).

The drilling procedure used to drill the foam blocks was the same used in the drilling of bovine bones. Several holes were made using a set of parameters and the temperature variation was obtained with the thermal camera at a distance of $1.5 \mathrm{~m}$ from the drilling area, as shown in Fig. 5.

The parameters considered in the drilling of ex vivo bovine bones and polyurethane foam blocks are presented in Table 2. All drilling tests were performed through customized automated system with total control of the involved parameters.

\subsection{Analysis of the experimental results: Bovine bones and foam blocks}

By using the thermographic camera the temperature generated in the drill bit during the drilling of the bovine femur and polyurethane foams was studied. It is a fact that the resistance of cortical bone tissue with friction causes temperature increase in bone tissue. The cellular damage and thermal necrosis in cortical bone caused by heat during drilling is reported to be evident at temperatures of $50^{\circ} \mathrm{C}^{2,15,23}$ The main advantage of a thermal camera is the ability to measure a whole temperature field. Furthermore, there are no concerns regarding proper contact or precise placement.

In this section, only the effect of drill speed and the temperature variation between different materials were investigated. The temperature variation was calculated and compared by subtracting the recorded temperature $\left(T_{R}\right)$ with the initial

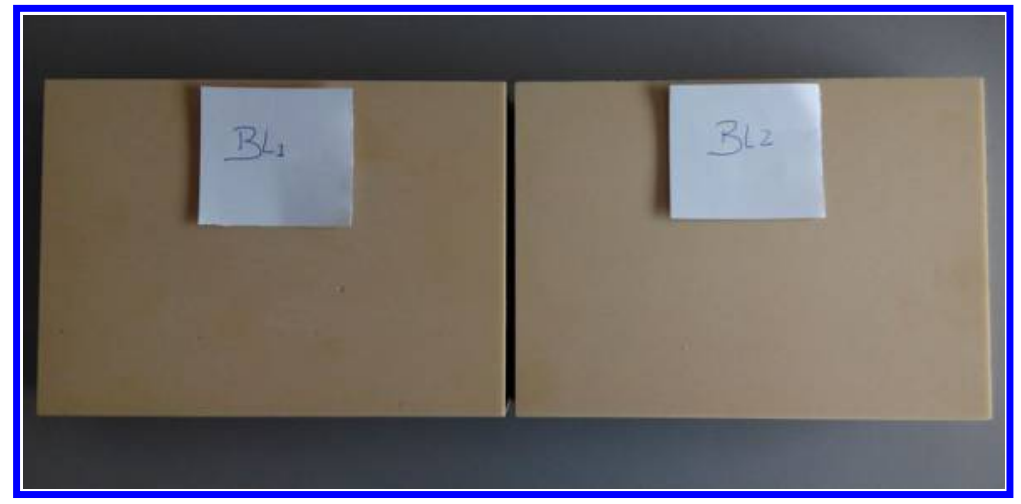

Fig. 4. Biomechanical foam blocks: Bl1 and Bl2. 


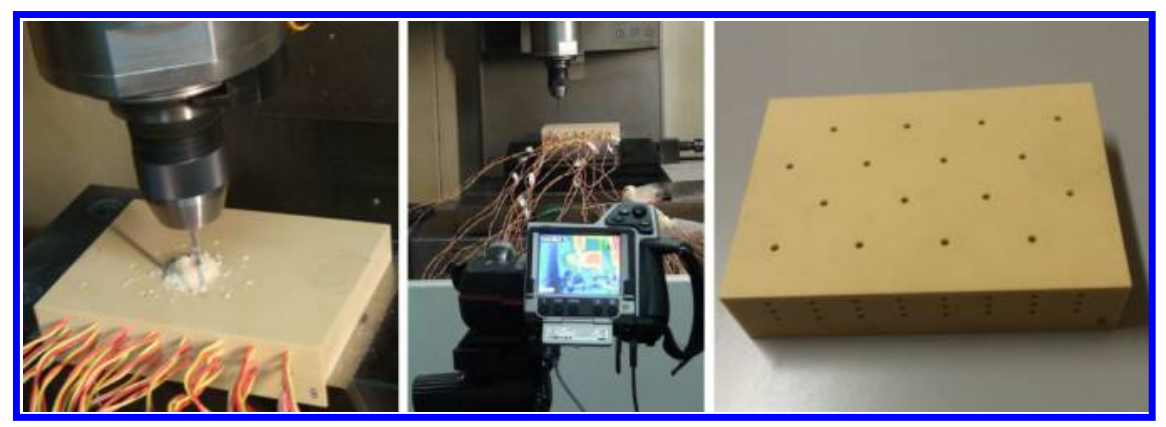

Fig. 5. Drilling process of biomechanical blocks.

temperature of the drill bit $\left(T_{0}\right)$ before each hole $\left(\Delta T\left({ }^{\circ} C\right)=T_{R}-T_{0}\right)$. The results were summarized using means and standard deviations. Table 3 shows the mean values obtained in different holes made with a drill speed of $800 \mathrm{rpm}$ and $900 \mathrm{rpm}$ and a constant feed-rate of $50 \mathrm{~mm} / \mathrm{min}$.

The bone blocks used in this study have been specifically designed to reproduce the physical properties of the cortical bone in terms of mechanical properties. The physical features of these synthetic bones are homogeneous throughout their volume, so as to obtain a good standardization of the procedures and to avoid possible mistakes in the temperature measurements. However, due to natural inhomogeneity of the animal origin bone tissue, there might be differences between such model and the ex vivo situation. Comparing the results obtained in both conditions, it was found that the temperature in the cutting tool is higher in holes made in polyurethane foam blocks, when compared with holes made in bovine femurs. These results were within what was expected, since the biomechanical blocks have a uniform platform over the whole model. The samples of bovine femur have an irregular geometry, with different cortical thickness along its diaphysis. Moreover, this is a fresh biological material with lower temperature inside, when compared with foams blocks. The own structure of the bone tissue itself provides a natural cooling to the cutting tool that block foam cannot offer.

With regard to the drill speed, it was found that increasing the drill speed from $800 \mathrm{rpm}$ to $900 \mathrm{rpm}$ did not promote any significant change in the temperature

Table 3. Variation of temperature from drill bit, before and after drilling.

\begin{tabular}{lccccc}
\hline & \multicolumn{3}{c}{ Foam block } & & \multicolumn{2}{c}{ Ex vivo bovine bones } \\
\cline { 2 - 3 } \cline { 5 - 6 } Statistics & Bl1 & Bl2 & & Samples $1,2,3,4$ & Samples 5,6,7,8 \\
\hline M \pm SD & $(n=8) 68.95 \pm 2.60$ & $(n=5) 69.88 \pm 2.00$ & & $(n=19) 39.47 \pm 3.73$ & $(n=25) 39.78 \pm 2.08$ \\
{$[$ Range $]$} & {$[65.9-73.6]$} & {$[66.8-71.8]$} & & {$[32.3-45.90]$} & {$[35.55-47.02]$} \\
\hline
\end{tabular}

Notes: M Mean value, SD Standard Deviation, $n$ number of holes. 
during drilling. The temperature variation is slightly higher in holes made with $900 \mathrm{rpm}$, however no significant difference was observed.

\section{Temperature Evolution Inside of the Bone}

In order to study the temperature distribution inside the bone tissue, thermocouples were used in the polyurethane foam blocks. For this purpose, two biomechanical blocks with the same characteristics used in the previous tests were chosen and identified as Bl3 and Bl4. During the drilling process, the temperature was evaluated inside the blocks by thermocouples and in the drill bit surface by thermal camera. In this section, the effect of different drill speeds, feed-rates and hole depth were studied.

\subsection{Temperature measurement system}

Bone temperature registers were performed at selected sites on the foam blocks. To measure the temperature inside the blocks several thermocouples (K-type, precision $0.4 \%$ ) with the range of $-270^{\circ} \mathrm{C}-1200^{\circ} \mathrm{C}$ were used. The thermocouples were placed in two opposite sides of the blocks and in adjacent positions to the drill bit. On one side of the block, the thermocouples were placed at the same distance from the drill bit (Side A), and on the other, thermocouples were placed at different distances (Side B), as shown in Fig. 6.

All thermocouples were tagged accordingly for each channel identification and respective connection to data acquisition system (Table 4). This experimental setup allowed to measure the temperatures within the blocks at different distances of the holes and along the drilling procedure duration time.

In accordance with the previous tests, the thermal camera was placed at the same distance from the drilling area and the holes were made with a CNC machine with total control of the parameters. For this study, different feed-rates and drill

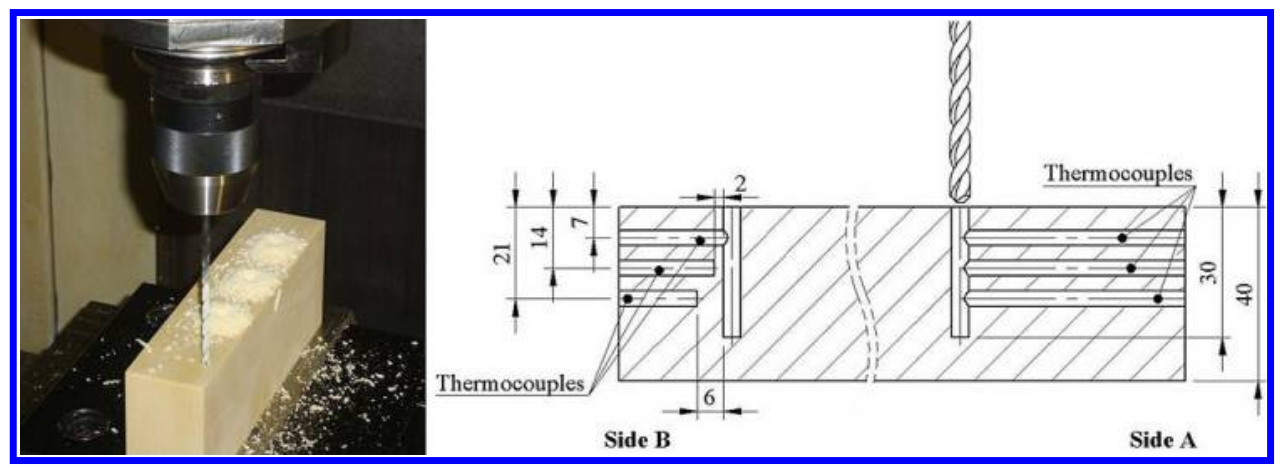

Fig. 6. Polyurethane foam block and illustration of the thermocouple positions. 
Table 4. Thermocouple labeling.

\begin{tabular}{lc}
\hline Thermocouple & \multicolumn{1}{c}{ Description } \\
\hline$A / B-T$ & Side A or B, drilling depths of $7 \mathrm{~mm}$ \\
$A / B-M$ & Side A or B, drilling depths of $14 \mathrm{~mm}$ \\
$A / B-R$ & Side A or B, drilling depths of $21 \mathrm{~mm}$ \\
\hline
\end{tabular}

speeds were considered in order to evaluate their influence on the drilling process (Table 5). All the other parameters were considered as a constant.

\subsection{Temperature evolution inside of the polyurethane foam blocks}

Through the thermocouples placed inside of the blocks at different distances it was possible to evaluate the temperature distribution throughout the drilling time, using different feed-rates with a constant drill speed and also different drill speeds with a constant feed-rate.

In Fig. 7, graphs (a)-(c) represent the obtained temperatures at different positions of thermocouples (Side A), for nine holes made with $30 \mathrm{~mm}$ of the depth; feed-rate: $V^{\prime}=25 \mathrm{~mm} / \mathrm{min}, V^{\prime \prime}=50 \mathrm{~mm} / \mathrm{min}$ and $V^{\prime \prime}=75 \mathrm{~mm} / \mathrm{min}$; and a constant drill speed: $\omega=800 \mathrm{rpm}$. The last graph (d) represents the typical curves of the temperature, at different positions of the thermocouples in Side B for one drilled hole. The results were obtained for a feed-rate equal to $25 \mathrm{~mm} / \mathrm{min}$ and constant drill speed $(\omega=800 \mathrm{rpm})$.

Figure 7 allows to explain the influence of feed-rate in drilling process of the polyurethane foam blocks. It is concluded that the increase in feed-rate causes lesser increase of the temperature in the polyurethane foam block. The same trend can be found in other studies using bovine and porcine bones. ${ }^{4,6,23-26,38}$ Comparing the levels of temperature for different feed-rates, it was observed that when the feed-rate was increased from $25 \mathrm{~mm} / \mathrm{min}$ to $50 \mathrm{~mm} / \mathrm{min}$, the temperature decreased in about $10.23 \%$ and when the feed-rate was increased from $25 \mathrm{~mm} / \mathrm{min}$ to $75 \mathrm{~mm} / \mathrm{min}$ the temperature decreases in about $17.23 \%$. The feed-rate represents the time of the heat source around the bone wall. Thus, the growth of feed-rate increases the rate of heat

Table 5. Parameters used in drilling experiments.

\begin{tabular}{lcc}
\hline & \multicolumn{2}{c}{ Foam block } \\
\cline { 2 - 3 } Parameters & $\mathrm{Bl} 3$ & $\mathrm{Bl} 4$ \\
\hline Drill diameter $(\mathrm{mm})$ & 4 & 4 \\
Drill point angle $\left(^{\circ}\right)$ & 118 & 118 \\
Depth of the holes $(\mathrm{mm})$ & 30 & 30 \\
Drill speed, $\omega(\mathrm{rpm})$ & $600,800,1200$ & 800 \\
Feed rate, $\mathrm{V}(\mathrm{mm} / \mathrm{min})$ & 50 & $25,50,75$ \\
Thermocouple & Yes & Yes \\
Thermal camera & Yes & Yes \\
\hline
\end{tabular}




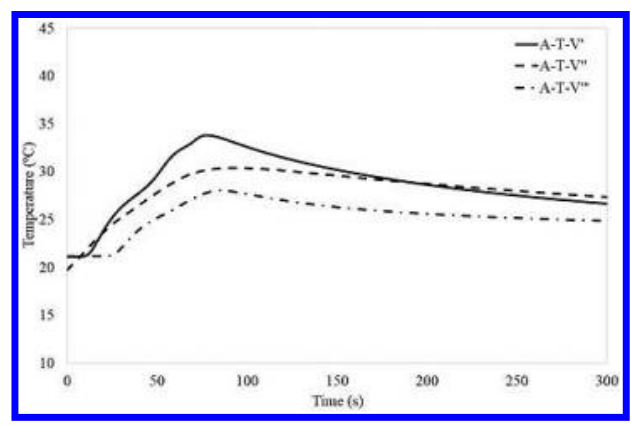

(a)

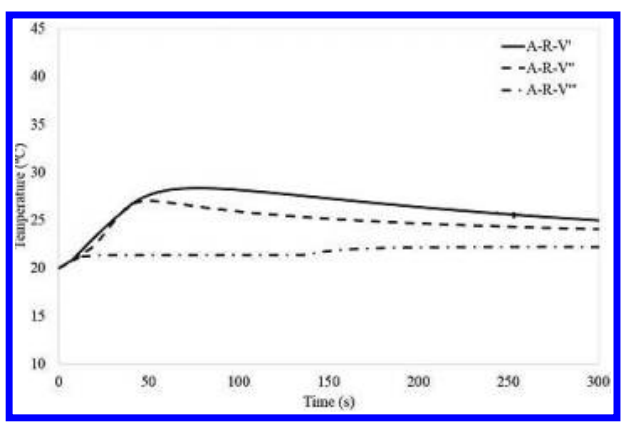

(c)

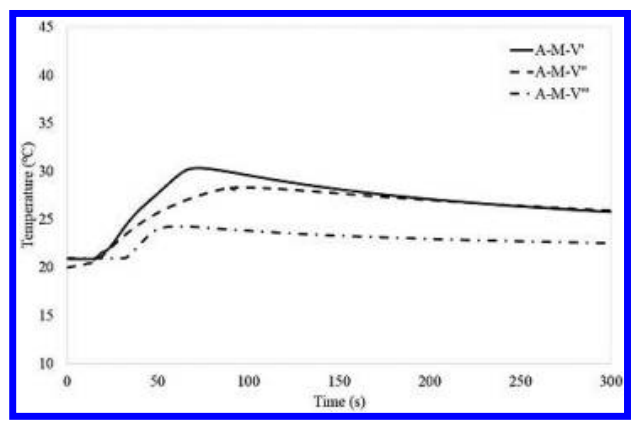

(b)

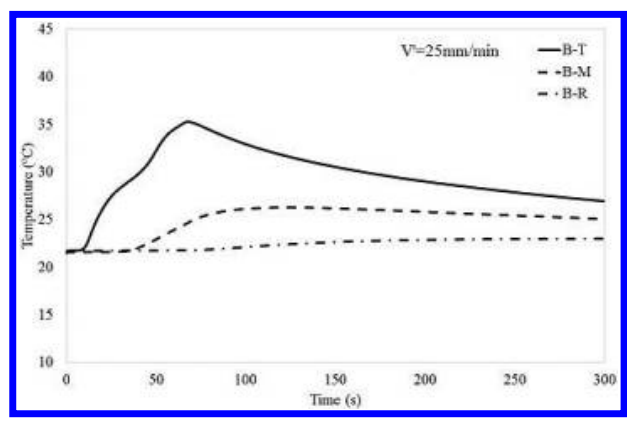

(d)

Fig. 7. Temperature evolution at different feed rates and positions of thermocouples.

generation but reduces the drilling time, which leads to a decrease of the total heat generated.

Different positions of thermocouples allowed concluding that the temperature decreases when the thermocouple is farthest from the hole. This event was expected because the polyurethane foam as well as bone material are bad heat conductors. In addition, this was confirmed in a study conducted by Lee et $a l .{ }^{4}$ that included a precise positioning of multiple thermocouples during drilling of bovine femurs. They concluded that the highest temperatures were recorded in the thermocouples closest to the drilled hole. For all thermal histories, it was also noted a similar trend with time; first an increase in time, reaching a peak (maximum) value, and then a slow decay. According to the authors Eriksson et al., ${ }^{10}$ the maximum temperature was far below critical level in all combinations of feed-rates during drilling.

In Fig. 8, graphs (a) and (b) represent the temperatures obtained at different positions of thermocouples (Side A), for two holes performed with $30 \mathrm{~mm}$ of depth; drill speed: $\omega^{\prime}=600 \mathrm{rpm}$ and $\omega^{\prime \prime}=1200 \mathrm{rpm}$; and a constant feed-rate: $V^{\prime \prime}=50 \mathrm{~mm} / \mathrm{min}$.

As shown in Fig. 8, the change in temperature also depends on the drill speed at a constant feed-rate. The temperature decreased in about $22.83 \%$ with increasing drill 


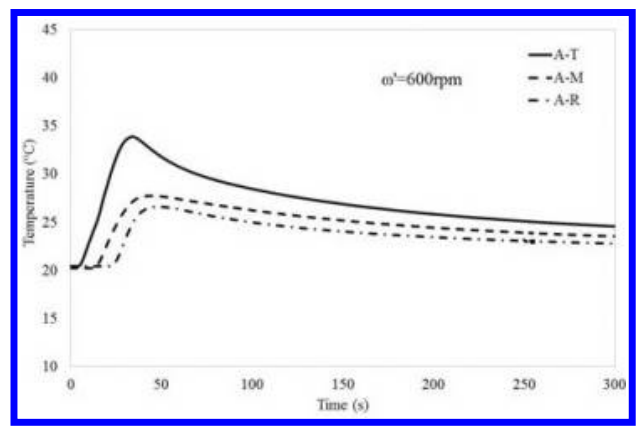

(a)

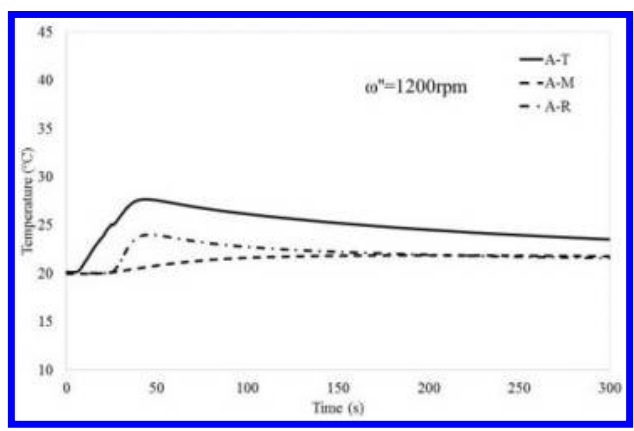

(b)

Fig. 8. Temperature evolution at different drill speeds.

speed from $600 \mathrm{rpm}$ to $1200 \mathrm{rpm}$. However, the literature review on the drill speed during bone drilling suggest no consistent trend. Some researchers suggest low drilling speed, $4,6,13,23,27$ while others suggest a decrease in the temperature with the increase of drill speed. ${ }^{15,26,28}$ The majority of the studies recommend high drill speed with larger force for minimum heat generation. ${ }^{11}$ According to the author Karmani, ${ }^{29}$ a possible factor in the temperature variation relationship and drill speed is that the rotational speed of a manual electric drill also depends on the force applied. Abouzgia and James ${ }^{30}$ measured the operating speeds of various drills and found them to be at times as low as $50 \%$ of the operating speed depending on the applied force. Therefore, apparent rotational speeds may not be the actual speeds.

Drilling depth also influences the temperature generated during drilling. Comparing the holes made with $8 \mathrm{~mm}$ and $30 \mathrm{~mm}$ of the depth, significantly higher temperatures were recorded for the holes with $30 \mathrm{~mm}$. The increase of the temperature with an increasing hole depth is explained by the friction effect. The frictional resistance offered by the compact cortical bone to the drill causes increases in temperature, while the thermal effect propagates to farther distances in the bone tissue samples. Similar conclusions were reached by the authors Hillery and Shuaib, ${ }^{15}$ Karaca et al. ${ }^{26}$ Lee et al. ${ }^{4}$

The present study is an experimental approach of selected drilling parameters on the heat generated during the drilling of bovine and synthetic bone. Several studies have been performed to analyze the temperature rise during drilling of animal bones, however no studies have exactly compared these results with commercially available artificial bones used in biomechanical studies. The validations of the experiments have been carried out by repeating the tests taking into account the selected drilling conditions and comparing the results with published scientific articles with similar approaches. Previous experimental and numerical methods developed by the authors of this work also allowed to compare and confirm the current results. 


\section{Conclusions}

In this study, temperature measurement systems were introduced to record realtime temperature changes during the drilling of ex vivo bovine bones and polyurethane foam blocks with different parameters. In our work, the comparison between the results, using different materials in similar drilling conditions, allows to obtain a confident level in the quality of the results with a same trend of conclusions. This research demonstrated that the appropriate combinations of different drill parameters can produce temperatures far below the critical values. It was concluded that when the feed-rate and the drill speed are higher, the increase of the bone temperature is lower and, independently, the maximum drill temperature increased with the increasing of hole depth. The values of temperature in the drilling process of ex vivo bone tissue were lower than the drilling process of solid rigid polyurethane foams, as expected. Through this study the application of high drill speeds are suggested, as well as high feed-rates and the reduction in contact area between the drill and bone. The polyurethane foam blocks have proved to be an appropriate material to test the bone drilling conditions with no need to resort to the biological tissues.

The obtained conclusions are similar using different materials with different methodologies (experimental, numerical or both), and the results tend to have a good correspondence, according to the measured values which compare means and standard deviations. Furthermore, increasing the amount of information from different measurements, the uncertainty of the results decreases with the results from the statistical calculation. The authors continue to develop more tests (experimental and numerical) to confirm the level of confidence and their results.

Automated drilling system with synthetic bone materials can be developed to minimize human error during bone drilling and reduce the incidence of osteonecrosis in the surrounding cortical bone tissue. With this research and with continuing to develop new methods to reduce the undesired mistakes during the bone drilling process in the surgical applications, we intend to contribute to the knowledge on the best drilling conditions.

\section{Conflict of Interest Statement}

The authors declare no conflicts of interest associated with the presented work.

\section{Acknowledgments}

This research was supported by the Portuguese Foundation of Science and Technology under research project UID/EMS/50022/2013. 


\section{References}

1. Li S, Wahab AA, Demirci E, Silberschmidt VV, Penetration of cutting tool into cortical bone: Experimental and numerical investigation of anisotropic mechanical behavior, J Biomech 47:1117-1126, 2014.

2. Eriksson AR, Albrektsson T, Albrektsson B, Heat caused by drilling cortical bone. Temperature measured in vivo in patients and animals, Acta Orthop Scand 55:629-631, 1984.

-3. Bachus KN, Rondina MT, Hutchinson DT, The effects of drilling force on cortical temperatures and their duration: An in vitro study, Med Eng Phys 22:685-691, 2000 .

-4. Lee J, Ozdoganlar B, Rabin Y, An experimental investigation on thermal exposure during bone drilling, Med Eng Phys 34:1510-1520, 2012.

-5. Sezek S, Aksakal B, Karaca F, Influence of drill parameters on bone temperature and necrosis: A FEM modelling and in vitro experiments, Comput Mater Sci 60:13-18, 2012 .

6. Lundskog J, Heat and bone tissue. An experimental investigation of the thermal properties of bone and threshold levels from thermal injury, Scand J Plast Reconstr Surg 6:5-75, 1972.

-7. Bonfield W, Li CH, The temperature dependence of the deformation of bone, J Biomech 7:323-329, 1968.

8. Möhlhenrich SC, Modabber A, Steiner T, Mitchell DA, Hölzle F, Heat generation and drill wear during dental implant site preparation: Systematic review, Br J Oral Maxillofac Surg 53:679-689, 2015.

-9. Scarano A, Piattelli A, Assenza B, Carinci F, Donato LD, Romani GL, Merla A, Infrared thermographic evaluation of temperature modifications induced during implant site preparation with cylindrical versus conical drills, Clin Implant Dent Relat Res 13:319-323, 2011.

10. Eriksson AR, Albrektsson T, Temperature threshold levels for heat induced bone tissue injury. A vital-microscopic study in the rabbit, J Prosthet Dent 50:101-107, 1983.

11. Pandey RK, Panda SS, Drilling of bone: A comprehensive review, J Clin Orthop Trauma 4:15-30, 2013.

12. Alam K, Mitrofanov AV, Silberschmidt VV, Finite element analysis of forces of plane cutting of cortical bone, Comput Mater Sci 46:738-743, 2009.

13. Xiashuang L, Wei Z, Junqiang W, Yuan D, Optimization of bone drilling process based on finite element analysis, Appl Therm Eng 108:211-220, 2016.

14. Marco M, Rodríguez-Millán M, Santiuste C, Giner E, Henar Miguélez M, A review on recent advances in numerical modelling of bone cutting, J Mech Behav Biomed Mater 44:179-201, 2015.

15. Hillery MT, Shuaib I, Temperature effects in the drilling of human and bovine bone, J Mater Process Technol 92:302-308, 1999.

16. den Dunnen S, Mulder L, Kerkhoffs GM, Dankelman J, Tuijthof GJ, Waterjet drilling in porcine bone: The effect of the nozzle diameter and bone architecture on the hole dimensions, J Mech Behav Biomed Mater 27:84-93, 2013.

17. Zelenov ES, Thermophysical properties of compact bone, Mech Compos Mater 21:1092-1095, 1985.

18. Augustin G, Zigman T, Davila S, Udilljak T, Brezak D, Babic S, Cortical bone drilling and thermal osteonecrosis, Clin Biomech 27:3313-3325, 2012.

19. Shim V, Boheme J, Josten C, Anderson I, Use of polyurethane foam in orthopaedic biomechanical experimentation and simulation, Zafar F, Sharmin E (eds.), Polyurethane, InTech, pp. 171-200, 2012. 
20. Vashishth D, Tanner KE, Bonfield W, Contribution, development and morphology of microcracking in cortical bone during crack propagation, J Biomech 33:1169-1174, 2000 .

21. Jacob CH, Berry JT, Pope MH, Hoagland FT, A study of bone machining process, J Biomech Eng 9:343-349, 1976.

22. Sawbones-Worldwide Leaders in Orthopaedic and Medical Models, Available at: www. sawbones.com (2015). Accessed 11 March 2015.

23. Augustin G, Davila S, Mihoci K, Udiljak T, Vedrina DS, Antabak A, Thermal osteonecrosis and bone drilling parameters revisited, Arch Orthop Trauma Surg 128:71-77, 2008.

24. Shin HC, Yoon YS, Bone temperature estimation during orthopaedic round bur milling operation, J Biomech 39:33-39, 2006.

25. Augustin G, Davila S, Udiljak T, Vedrina DS, Bagatin D, Determination of spatial distribution of increase in bone temperature during drilling by infrared thermography: Preliminary report, Arch Orthop Trauma Surg 129:703-609, 2009.

26. Karaca F, Aksakal B, Kom M, Influence of orthopaedic drilling parameters on temperature and histopathology of bovine tibia: An in vitro study, Med Eng Phys 33:1221-1227, 2011.

27. Vaughan RC, Peyton FA, The influence of rotational speed on temperature rise during cavity preparation, J Dent Res 30:737-744, 1951.

28. Sharawy M, Misch CE, Weller N, Tehemar S, Heat generation during implant drilling: The significance of motor speed, J Oral Maxillofac Surg 60:1160-1169, 2002.

29. Karmani S, The thermal properties of bone and the effects of surgical intervention, Curr Orthop 20:52-58, 2006.

30. Abouzgia MB, James F, Temperature rise during drilling through bone, Int $J$ Oral Maxillofac Implants 12:342-352, 1997.

31. Bedrettin CS, Guhan D, Bahar G, Ergun K, Imad S, Effects of irrigation temperature on heat control in vitro at different drilling depths, Clin Oral Implants Res 20:294-298, 2009 .

32. Fernandes MG, Fonseca EMM, Natal R, Thermal analysis during bone drilling using rigid polyurethane foams: Numerical and experimental methodologies, J Braz Soc Mech Sci Eng 38:1855-1863, 2016.

33. Fernandes MG, Fonseca EMM, Natal RJ, Influence of bone drilling parameters on the thermal stress distribution, Silva Gomes JF, Meguid SA (eds.), Proc 5th Int Conf Integrity-Reliability-Failure, Porto, pp. 517-528, 2016.

34. Fernandes MG, Fonseca EMM, Natal R, Thermo-mechanical stresses distribution on bone drilling: Numerical and experimental procedures, Proc IMechE Part L: J Mater Des Appl 2017. doi: 10.1177/1464420716689337 (in press).

35. Fernandes MG, Fonseca EMM, Jorge RN, Three-dimensional dynamic finite element and experimental models for drilling processes, Proc IMechE Part L: J Mater Des Appl 2015. doi:10.1177/1464420715609363 (in press).

36. Fernandes MG, Natal R, Fonseca EMM, Analysis of stresses in drilled composite materials, in Bioengineering (ENBENG), IEEE 4th Portuguese Meeting, Porto, pp. 1-4, 2015.

37. Fernandes MG, Fonseca EMM, Jorge RN, Vaz M, Dias MI, Composite materials and bovine cortical bone drilling: Thermal experimental analysis, Silva Gomes JF, Meguid SA (eds.), Proc 6th Int Conf Mechanics and Materials in Design, Azores, pp. 691-692, 2015.

38. Fernandes MG, Natal RJ, Fonseca EMM, Dias MI, Temperature assessment in the drilling of ex vivo bovine and porcine cortical bone tissue, in Jorge $\mathrm{N}$ et al. (eds.), Proc. 
Int. Conf. Clinical and BioEngineering for Women's Health, CRC Press, Taylor \& Francis Group, London, pp. 159-163, 2016.

39. Tu YK, Chen LW, Ciou JS, Hsiao CK, Chen YC, Finite element simulations of bone temperature rise during bone drilling based on a bone analog, J Med Biol Eng 33:269-274, 2013.

40. Feldmann A, Anso J, Bell B, Williamson T, Gavaghan K, Gerber N, Rohrbach H, Weber S, Zysset P, Temperature prediction model for bone drilling based on density distribution and in vivo experiments for minimally invasive robotic cochlear implantation, Ann Biomed Eng 44(5):1576-1586, 2016.

41. Pandey RK, Panda SS, Drilling of bone: A comprehensive review, J Clin Orthop Trauma 4:15-30, 2013.

42. Campana V, Milano G, Pagano E, Barba M, Cicione C, Salonna G, Lattanzi W, Logroscino G, Bone substitutes in orthopaedic surgery: From basic science to clinical practice, J Mater Sci: Mater Med 25:2445-2461, 2014.

43. Yuehuei HA, Christopher VB, General considerations of mechanical testing. In: Yuehuei HA, Robert AD (eds), Mechanical Testing of Bone and the Bone-Implant Interface, CRC Press, New York, pp. 119-131, 2000. 